\title{
Cognitive and Functional Outcome among Hospitalized Intracerebral Haemorrhage Patients in West Java's Top Referral Hospital
}

\author{
Ilham Bagas Setyawan, ${ }^{1}$ Paulus Anam Ong, ${ }^{2}$ M. Zafrullah Arifin ${ }^{3}$ \\ ${ }^{1}$ Faculty of Medicine Universitas Padjadjaran, ${ }^{2}$ Department of Neurology Faculty of Medicine \\ Universitas Padjadjaran/Dr. Hasan Sadikin General Hospital, Bandung, Indonesia, ${ }^{3}$ Department of \\ Neurosurgery Faculty of Medicine Universitas Padjadjaran/Dr. Hasan Sadikin General Hospital, \\ Bandung, Indonesia
}

\begin{abstract}
Background: Stroke is the highest cause of disability in adults. Disability and cognitive function impairment cause dependency and decreasing quality of life. The objectives of this study was to describe the outcome of functional and cognitive function among intracerebral haemorrhage patients admitted to Dr. Hasan Sadikin General Hospital Bandung in 2013.

Methods: This study was a quantitative descriptive study, conducted from October 2016 to August 2017. Data were collected retrospectively with total sampling method from medical records of intracerebral haemorrhage patients admitted to Dr. Hasan Sadikin General Hospital in 2013 assessed with the Montreal Cognitive Assessment-Indonesian Version (MoCA-INA) and Barthel Index. Patients with incomplete medical records , severe aphasia, severe sensoric-motoric impairment, and decreased consciousness were excluded in this study. Data were analyzed using Microsoft Office Excel 2010 and presented in percentage.

Results: Out of the 26 subjects, 11 were men and 15 women, who were in the age range of 45-54 years $(42.3 \%)$, with low education level $(61.5 \%)$, and unemployed $(61.5 \%)$ had the highest prevalence on subjects studied. Hypertension was the most common risk factor (78\%). Most subjects had cognitive function impairment (69.2\%) with delayed memory function as the most common impairment domain found $(84.6 \%)$, followed by visuospatial/executive function $(69.2 \%)$. Most subjects had a high score of dependence according to the Barthel test (61.5\%).

Conclusions: Two third of intracerebral haemorrhage patients have cognitive function impairment and functional dependence. Memory function is the most common impaired cognitive functional domain.
\end{abstract}

Keywords: Cognitive outcome, functional outcome, haemorrhagic stroke

\section{Introduction}

According to the World Health Organization (WHO), stroke is defined as a clinical manifestation of cerebral dysfunction, either focal or global that occurs rapidly, sustained more than 24 hours or until causing death, without cause other than cerebral vascular origin. Meanwhile, according to the American Heart Association (AHA), stroke is defined as an acute neurologic dysfunction caused by ischaemia and haemorrhage, occuring more than 24 hours or until causing death. ${ }^{1}$

Stroke is the most common cause of disability in adults. ${ }^{2}$ Stroke contributes to 43.5 million (3.2\%) Disability Adjusted Life Years (DALYs) annualy worldwide. DALYs is defined as the potential number of years lost due to premature death and productive days lost from disability.3 Neurologic deficit is the cause of disability in stroke. Neurologic deficit that occurs depends on severity and site of lesion, ${ }^{4,5}$ and may present as cognitive function impairment, sensory impairment, or motor impairment. ${ }^{5}$

The Montreal Cognitive Assessment (MoCA) is one of the widely used screening instruments in clinical setting to detect presence of cognitive function in stroke patients. ${ }^{6}$ This instrument shows high sensitivity to measure cognitive function impairment in mild stroke because it calculates executive functions. ${ }^{7}$ When cognitive dysfunction is present, rapid detection to prevent cognitive decline by directing treatment into cognitive rehabilitation is needed. ${ }^{6}$ Moreover, during rehabilitation, assessment of functional outcome needs to be carried oout towards stroke patients

Correspondence: Ilham Bagas Setyawan, Faculty of Medicine, Universitas Padjadjaran, Jalan Raya Bandung-Sumedang Km.21, Jatinangor, Sumedang, Indonesia, Email: bagasetyawan9@gmail.com. 
in order to determine improvement for further rehabilitation management. ${ }^{8}$ The Barthel Index is an instrument that measures disability degree or functional outcome based on the ability to carry out daily activity independently. Barthel Index is commonly used because the measurement is simple and does not necessarily need a specially trained observer as it is simply observing the ability to carry out basic daily tasks. ${ }^{9}$

A study regarding cognitive function of stroke patients using the MoCA instrument and functional outcome using the Barthel Index was never performed at Dr. Hasan Sadikin General Hospital. Moreover, cognitive and functional measurement is vital for further rehabilitation of stroke patients. Hence, the study of descriptive cognitive and functional outcome in haemorrhagic stroke patients is needed. The objective of this study was aimed to describe the cognitive and functional outcome among intracerebral haemorrhage patients admitted to Dr. Hasan Sadikin General Hospital Bandung.

\section{Methods}

A descriptive quantitative study was carried out from October 2016 to August 2017 using secondary data from medical records of intracerebral haemorrhage patients admitted to Dr. Hasan Sadikin General Hospital Bandung from January 2013 to December 2013. The measurements of cognitive and functional outcome were elaborated by using the Montreal Cognitive Assessment-Indonesian Version (MoCA-INA), with assessment results categorized as impaired (MoCA-INA score $<26$ ) and normal cognitive function (MoCAINA score 26-30). Moreover, the functional outcome was measured by using the Barthel Index instrument, and categorized by degree of independence.

The study subjects were medical records of intracerebral haemorrhage patients admitted to Dr. Hasan Sadikin General Hospital Bandung from January 2013 to December 2013, who met the inclusion criteria as patients with the MoCA-INA and Barthel Index assessment. Medical records with incomplete data, severe aphasia, severe sensory or motor impairment, and decreased consciousness were excluded from this study.

This study was approved by the Commission of Ethics Faculty of Medicine Universitas Padjadjaran with number of ethics 354/ UN6.C.10/PN/2017. Data were analyzed using the Microsoft Office Excel 2010., and were presented in percentage.

\section{Results}

During the study period, 68 intracerebral haemorrhage patients were hospitalized at Dr. Hasan Sadikin General Hospital Bandung, but only 26 patients were eligible for further analysis. The excluded subjects were 29 subjects with decreased consciousness, 9 subjects with severe aphasia, and 4 subjects with incomplete medical record data.

Female patients were slightly more dominant than males (57.7 vs. $42.3 \%$ ). More than half of the subjects were of the age range between 45-54 years. Subjects with low education level (uneducated, did not finish elementary, and elementary) had the highest prevalence (61.5\%). Subjects who were unemployed had the highest prevalance with 16 patients $(61.5 \%)$. Subjects with hypertension as the risk factor had the highest prevalence with 19 patients (73.1\%) (Table 1).

Moreover, i was obvious that the majority of patients $(69.2 \%)$ suffered from cognitive function impairment (Table 2). Furthermore, the affected domain of cognitive function showed that delayed memory was the most common impaired cognitive function domain with 22 patients (84.6\%), followed by visuospatial/executive with 18 patients (69.2\%), and abstraction with 17 patients (65.4\%) (Table 3).

Additionally, assessments of functional outcome were performed by using Barthel Index assessment for the patient medical records, with assessment results categorized by the degree of independence. Based on data of the functional outcome in intracerebral haemorrhage patients, $61.5 \%$ patients had higher dependence (moderate, severe, total dependence) (Table 4).

\section{Discussion}

In this study, intracerebral haemorrhage patients were more prevalent in women. This finding was consistent with a retrospective study conducted by Toglia et al. ${ }^{10}$ However, it was insignificant due to a slight difference in frequency. On the other hand, several other studies found that it was more often found in men. ${ }^{11}$ The age of study subjects was mostly between 45-54 years, which was comparable to a study by 0'Donnell et al. ${ }^{12}$ in 2016, which showed the highest prevalence of stroke is also on a similar age range.

Based on an observational cohort study 


\begin{tabular}{|c|c|c|}
\hline Patient Characteristics & Number $(n=26)$ & Percentage (\%) \\
\hline \multicolumn{3}{|l|}{ Sex } \\
\hline Male & 11 & 42.3 \\
\hline Female & 15 & 57.7 \\
\hline \multicolumn{3}{|l|}{ Age (Years) } \\
\hline $15-24$ & 1 & 3.8 \\
\hline $25-34$ & 0 & 0 \\
\hline $35-44$ & 4 & 15.4 \\
\hline $45-54$ & 15 & 57.7 \\
\hline $55-64$ & 5 & 19.2 \\
\hline$\geq 65$ & 1 & 3.9 \\
\hline \multicolumn{3}{|l|}{ Education Level } \\
\hline Uneducated & 1 & 3.9 \\
\hline Did not pass elementary & 6 & 23.1 \\
\hline Elementary & 9 & 34.6 \\
\hline Junior High School & 3 & 11.5 \\
\hline Senior High School & 7 & 26.9 \\
\hline Diploma/University & 118 & 100 \\
\hline Graduate & 0 & 0 \\
\hline \multicolumn{3}{|l|}{ Occupation } \\
\hline Unemployed & 16 & 61.5 \\
\hline Office worker & 2 & 7.7 \\
\hline Entrepreneur/merchant & 2 & 7.7 \\
\hline Farmer/fisherman/laborer & 4 & 15.4 \\
\hline Others & 2 & 7.7 \\
\hline \multicolumn{3}{|l|}{ Risk factors } \\
\hline Hypertension & 19 & 73.1 \\
\hline Diabetes melitus & 3 & 11.5 \\
\hline Heart disease & 1 & 3.8 \\
\hline Dyslipidemia & 5 & 19.2 \\
\hline Smoking & 7 & 26.9 \\
\hline Recurrent stroke & 11 & 42.3 \\
\hline Blood abnormality & 2 & 7.7 \\
\hline Blood vessel abnormality & 1 & 3.8 \\
\hline
\end{tabular}

conducted by the Department of Neurology Dijon University, France, ${ }^{13}$ during the period of 2010-2012, it found that stroke patients mostly come from a low education level and were unemployed. This study also found that as much as $61.5 \%$ of subjects had low education level (uneducated, did not finish elementary, elementary) and were unemployed. Results from the Basic Health Research (Riskedas) ${ }^{14}$ in 2013 showed similar results in regard to education level and employment. The cognitive function might be affected by the education 
Table 2 Description of Cognitive Function in Study Subjects

\begin{tabular}{lcc}
\hline \multicolumn{1}{c}{ MoCA-INA Score } & Frequency $(\mathbf{n = 2 6 )}$ & Percentage (\%) \\
\hline Score $<26$ (Impaired) & 18 & 69.2 \\
Score 26-30 (Normal) & 8 & 30.8 \\
Total & 26 & 100 \\
\hline
\end{tabular}

Table 3 Impairment of Cognitive Function Domain in Study Subjects

\begin{tabular}{lcc}
\hline \multicolumn{1}{c}{ Cognitive Function Domain } & Frequency $(\mathbf{n = 2 6 )}$ & Percentage (\%) \\
\hline Visuospatial/executive (5) & 18 & 69.2 \\
Naming (3) & 10 & 38.5 \\
Attention (6) & 16 & 61.5 \\
Language (3) & 13 & 50.0 \\
Abstraction (2) & 17 & 65.4 \\
Delayed memory (5) & 22 & 84.6 \\
Orientation (6) & 13 & 50.0 \\
\hline
\end{tabular}

level. Thus, when a stroke patient is identified with low education level, one extra point is given in the MoCA-INA assessment. ${ }^{15}$ The risk factor has an important role in the disease progression. In this study, 78\% of respondents with hypertension as a risk factor had the highest prevalence. This is in line with a stroke epidemiology study conducted by Mukherjee et al. ${ }^{3}$ which showed that hypertension is a risk factor with the highest prevalence in stroke.

This study showed that intracerebral haemorrhage at Dr. Hasan Sadikin General Hospital mostly resulted in cognitive function impairment with $69.2 \%$ of cases. This is consistent with a retrospective study conducted by Chan et al. ${ }^{11}$ regarding a cognitive status with the MoCA in acute stroke patients in 2013 that most haemorrhagic stroke patients have a cognitive function impairment. A retrospective study performed by Toglia et al. ${ }^{10}$ regarding the MMSE and MoCA showed delayed memory function followed by visuospatial/executive function as the most common impaired cognitive function in stroke patients. A cohort study by Jokinen et al. ${ }^{16}$ also showed memory, visuospatial, and executive functions are the most commonly impaired. It is in line in with this study which showed delayed memory function is the most often impaired domain for as much as $84.6 \%$ followed by visuospatial/executive function for as much as $69.2 \%$.

A study in China by Pei et al. ${ }^{17}$ which studied factors associated with activities of daily living among the disabled elders with stroke using the Barthel Index as instrument showed that stroke patients who experienced higher dependence (total, severe, and mild dependence) had higher prevalence. The same finding is also found in this study that haemorrhagic stroke patients who experienced dependence dominates for as much as $61.5 \%$.

This study has several limitations. Among the 68 potential subjects, only 26 fulfilled

Table 4 Functional Outcome in Intracerebral Haemorrhage Patients

\begin{tabular}{lccc}
\hline \multicolumn{1}{c}{ Barthel Index Score } & Interpretation & $\begin{array}{c}\text { Frequency } \\
(\mathbf{n = 2 6 )}\end{array}$ & $\begin{array}{c}\text { Percentage } \\
\text { (\%) }\end{array}$ \\
\hline Score $0-20$ & Total Dependence & 10 & 38.5 \\
Score $25-40$ & Severe Dependence & 1 & 3.8 \\
Score $45-55$ & Moderate Dependence & 5 & 19.2 \\
Score $60-95$ & Mild Dependence & 10 & 38.5 \\
Score 100 & Independent & 0 & 0 \\
Total & & 26 & 100 \\
\hline
\end{tabular}


the inclusion criteria. It might be due to the natural history of disease, since most of the intracerebral haemorrhagic stroke patients were admitted with decreased consciusness thus the MoCA-INA assessment cannot be performed in an acute stroke condition. Besides this study was conducted in 2017, on the otherhand the obtained data was from 2013. Hence, these conditions might influence the study results.

As a conclusion, two third of intracerebral haemorrhage patients who survived in the acute phase have cognitive function impairment. Delayed memory function is the most common impaired cognitive function. Most of the intracerebral haemorrhage patients experience dependence, where more than half have experienced higher dependence (total, severe, moderate dependence).

\section{References}

1. Sacco RL, Kasner SE, Broderick JP, Caplan LR, Connors JJ, Culebras A, etal. An updated definition of stroke for the 21st century: a statement for healthcare professionals from the American Heart Association/ American Stroke Association. Stroke. 2013;44(7):2064-89.

2. Mendis S. Stroke disability and rehabilitation of stroke: World Health Organization perspective. Int J Stroke. 2013;8(1):3-4.

3. Mukherjee D, Patil CG. Epidemiology and the global burden of stroke. World Neurosurg. 2011;76(6 Suppl):S85-90.

4. Gorelick PB, Scuteri A, Black SE, DeCarli C, Greenberg SM, Iadecola C, et al. Vascular contributions to cognitive impairment and dementia: a statement for healthcare professionals from the American Heart Association/American Stroke Association. Stroke. 2011;42(9):2672-713.

5. Corbetta M, Ramsey L, Callejas A, Baldassarre A, Hacker CD, Siegel JS, et al. Common behavioral clusters and subcortical anatomy in stroke. Neuron. 2015;85(5):927-41.

6. Friedman L. Evaluating the Montreal Cognitive Assessment (MoCA) and the Mini Mental State Exam (MMSE) for cognitive impairment post stroke: A validation study against the Cognistat [thesis]. London, Ontario, Kanada: The University of Western Ontario; 2012.

7. Stolwyk RJ, O’Neill MH, McKay AJ, Wong DK. Are Cognitive Screening Tools Sensitive and Specific Enough for Use After Stroke?
Stroke. 2014;45(10):3129-34.

8. Meyer MJ, Pereira S, McClure A, Teasell R, Thind A, Koval J, et al. A systematic review of studies reporting multivariable models to predict functional outcomes after poststroke inpatient rehabilitation. Disabil Rehabil. 2015;37(15):1316-23.

9. Duffy L, Gajree S, Langhorne P, Stott DJ, Quinn TJ. Reliability (Inter-rater Agreement) of the Barthel Index for Assessment of Stroke Survivors. Stroke. 2013;44(2):462-8.

10. Toglia J, Fitzgerald KA, O'Dell MW, Mastrogiovanni AR, Lin CD. The MiniMental State Examination and Montreal Cognitive Assessment in persons with mild subacute stroke: relationship to functional outcome. Arch Phys Med Rehabil. 2011;92(5):792-8.

11. Chan E, Khan S, Oliver R, Gill SK, Werring DJ, Cipolotti L. Underestimation of cognitive impairments by the Montreal cognitive assessment (MoCA) in an acute stroke unit population. J Neurol Sci. 2014;343(12):176-9.

12. O'Donnell MJ, Chin SL, Rangarajan S, Xavier D, Liu L, Zhang $\mathrm{H}$, et al. Global and regional effects of potentially modifiable risk factors associated with acute stroke in 32 countries (INTERSTROKE): a case-control study. Lancet. 2016;388(10046):761-75.

13. Jacquin A, Binquet $C$, Rouaud O, GraulePetot A, Daubail B, Osseby $\mathrm{G}-\mathrm{V}$, et al. Post-stroke cognitive impairment: high prevalence and determining factors in a cohort of mild stroke. J Alzheimers Dis. 2014;40(4):1029-38.

14. Kementrian Kesehatan Republik Indonesia. Riset Kesehatan Dasar. Jakarta: Badan Penelitian dan Pengembangan Kesehatan Kementrian Kesehatan RI; 2013.

15. Julayanont $P$, Phillips N, Chertkow $H$, Nasreddine ZS. Montreal Cognitive Assessment (MoCA): concept and clinical review. In: Larner A (eds). Cognitive screening instruments. London: Springer; 2013. p. 111-51.

16. Jokinen H, Melkas S, Ylikoski R, Pohjasvaara T, Kaste M, Erkinjuntti T, et al. Post-stroke cognitive impairment is common even after successful clinical recovery. Eur J Neurol. 2015;22(9):1288-94.

17. Pei L, Zang X-Y, Wang Y, Chai Q-W, Wang J-Y, Sun C-Y, et al. Factors associated with activities of daily living among the disabled elders with stroke. International Journal of Nursing Sciences. 2016;3(1):29-34. 